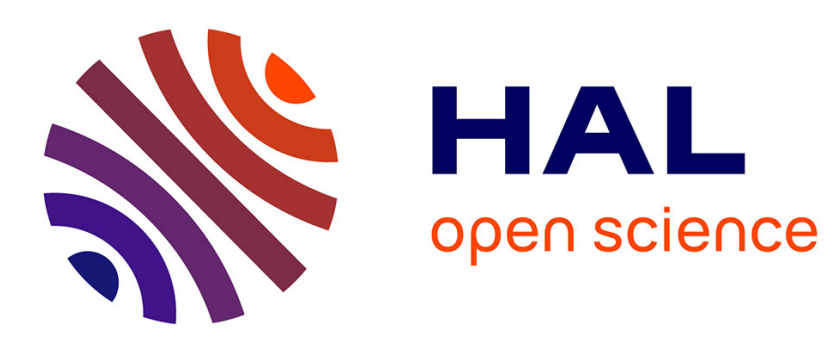

\title{
Oral voriconazole and miconazole oral gel produce comparable effects on the pharmacokinetics and pharmacodynamics of etoricoxib
}

Ville V. Hynninen, Klaus T. Olkkola, Pertti J. Neuvonen, Kari Laine

\section{- To cite this version:}

Ville V. Hynninen, Klaus T. Olkkola, Pertti J. Neuvonen, Kari Laine. Oral voriconazole and miconazole oral gel produce comparable effects on the pharmacokinetics and pharmacodynamics of etoricoxib. European Journal of Clinical Pharmacology, 2008, 65 (1), pp.89-95. 10.1007/s00228-008-0556-9 . hal-00477922

\section{HAL Id: hal-00477922 \\ https://hal.science/hal-00477922}

Submitted on 30 Apr 2010

HAL is a multi-disciplinary open access archive for the deposit and dissemination of scientific research documents, whether they are published or not. The documents may come from teaching and research institutions in France or abroad, or from public or private research centers.
L'archive ouverte pluridisciplinaire HAL, est destinée au dépôt et à la diffusion de documents scientifiques de niveau recherche, publiés ou non, émanant des établissements d'enseignement et de recherche français ou étrangers, des laboratoires publics ou privés. 


\title{
Oral voriconazole and miconazole oral gel produce comparable effects on the pharmacokinetics and pharmacodynamics of etoricoxib
}

\author{
Ville V. Hynninen • Klaus T. Olkkola • \\ Pertti J. Neuvonen • Kari Laine
}

Received: 20 May 2008 / Accepted: 18 August 2008 / Published online: 9 September 2008

(C) Springer-Verlag 2008

\begin{abstract}
Purpose The effect of topical miconazole oral gel and systemic oral voriconazole on the pharmacokinetics of oral etoricoxib was studied in 12 healthy volunteers.

Methods Plasma concentrations of etoricoxib, miconazole, voriconazole, and thromboxane $\mathrm{B}_{2}$ generation were followed after ingestion of $60 \mathrm{mg}$ etoricoxib without pretreatment, after topical administration of miconazole oral gel $(85 \mathrm{mg} \times$ 3,3 days), or after oral voriconazole $(400 \mathrm{mg} \times 2,1$ st day, $200 \mathrm{mg} \times 2$, 2nd day).

Results Etoricoxib area under the plasma concentrationtime curve $\left(\mathrm{AUC}_{0-\infty}\right)$ and maximum plasma concentration $\left(\mathrm{C}_{\max }\right)$ geometric mean ratios (GMR) with/without miconazole were $1.69\{90 \%$ confidence interval $(\mathrm{CI}) ; 1.46-1.92\}$ and 1.12 (90\% CI; 0.99-1.25), respectively, and corresponding GMRs with/without voriconazole were 1.49 (90\% CI; 1.37-1.61) and 1.19 (90\% CI; 1.08-1.31), respectively.
\end{abstract}

V. V. Hynninen $(\bowtie) \cdot K$. Laine

Department of Pharmacology,

Drug Development and Therapeutics, University of Turku, Itäinen Pitkäkatu 4B,

20520 Turku, Finland

e-mail: vilhyn@utu.fi

\section{K. T. Olkkola}

Department of Anesthesiology, Intensive Care,

Emergency Care and Pain Medicine, Turku University Hospital,

Kiinanmyllynkatu 4-8,

20520 Turku, Finland

\section{P. J. Neuvonen}

Department of Clinical Pharmacology,

University of Helsinki and Helsinki University Hospital,

Haartmaninkatu 4,

00290 Helsinki, Finland
Conclusions Miconazole oral gel and oral voriconazole produced comparable increase in the exposure to etoricoxib, presumably via CYP3A inhibition.

Keywords Etoricoxib - Voriconazole · Miconazole · Pharmacokinetics · CYP3A

\section{Introduction}

Etoricoxib is a member of the selective cyclooxygenase (COX)-2-inhibitor family of nonsteroidal anti-inflammatory drugs (NSAIDs) that are widely used to treat pain and inflammation. Oral bioavailability of etoricoxib tablets is nearly $100 \%$ [1]. Despite its negligible first-pass metabolism, the elimination of etoricoxib is characterized by extensive metabolism, with less than $1 \%$ of an oral dose detected as unchanged drug in urine [2]. In vitro studies indicate that cytochrome P450 3A (CYP3A) is the most important enzyme catalyzing the primary metabolic pathway of etoricoxib (60\%), with CYP2C9, CYP2D6, CYP1A2, and CYP2C19 each contributing about 10\% [3].

Miconazole is an imidazole antifungal, which was originally developed as a systemic antifungal agent during the 1970s, but due to its low oral bioavailability and high incidence of adverse effects in systemic use, other antifungals have replaced miconazole for most of its systemic indications. Nowadays, miconazole is almost solely used as a topical preparation, e.g., as an oral gel for treating oral fungal infections. In vitro, miconazole inhibits many CYPs, namely, CYP3A, CYP2C9, CYP2C19, CYP1A2, CYP2A6, CYP2B6, and CYP2D6 [4-6], and in vivo the interaction between systemically administered miconazole and the CYP2C9 substrate, warfarin, is well established [7]. Topically applied miconazole, such as oral gel, is generally 
considered a safer treatment with regard to drug interactions, because only small amount of miconazole is absorbed after miconazole oral gel application. Several previous case reports have reported that miconazole oral gel can also enhance warfarin-induced anticoagulation, probably due to the inhibition of CYP2C9 [8-10], but very little, if anything is known about its in vivo inhibition with regard to CYP3A.

Voriconazole is a novel triazole antifungal agent used both intravenously and orally to treat invasive fungal infections. Voriconazole is an inhibitor of CYP3A, CYP2C9, and CYP2C19 and is able to cause even manifold increase in plasma concentrations of drugs, which are metabolized by these CYP enzymes [11-13]. Because miconazole inhibits CYP3A and other CYP enzymes responsible for the primary oxidative metabolism of etoricoxib in vitro, we found it important to study whether miconazole from oral gel preparation is also liable to impair CYP-mediated metabolism of etoricoxib and to increase its concentrations. The effects of miconazole oral gel on the pharmacokinetics of etoricoxib were compared with the effects of orally administered, strong CYP inhibitor, voriconazole. In addition, we wanted to study whether increased exposure to etoricoxib might lead to a loss of selective COX-2 inhibition (i.e., inhibition of COX-1) of etoricoxib, by using a generation of thromboxane $\mathrm{B}_{2}$ $\left(\mathrm{TxB}_{2}\right)$ during whole-blood clotting as an index of COX-1 activity [14].

\section{Methods}

Subjects

Twelve healthy male volunteers (age range 20-28 years; weight range $61-92 \mathrm{~kg}$ ) participated in the study. Each subject was ascertained to be in good health as assessed by a medical history, physical examination, and routine laboratory tests. The volunteers were not using any continuous medication, and all were nonsmokers. The subjects received both verbal and written information on the study, and written informed consent was obtained. The study protocol was approved by the Ethics Committee of the Hospital District of Southwest Finland and the National Agency for Medicines, Finland.

\section{Study design}

The study was carried out in a Latin-square, open-label, randomized, three-phase crossover design, with a washout period of 2 weeks between phases. The volunteers were given either no pretreatment (control phase) or oral voriconazole (voriconazole phase) for 2 days or oral miconazole gel (miconazole phase) for 3 days in a randomized manner. The dose of voriconazole (Vfend $200 \mathrm{mg}$ tablet; Pfizer, Illertissen, Germany) was $400 \mathrm{mg}$ every $12 \mathrm{~h}$ for 1 day and then $200 \mathrm{mg}$ every $12 \mathrm{~h}$ for 1 additional day. Miconazole oral gel dose (Daktarin 2\% oral gel; Orion Pharma, Espoo, Finland) was $3.5 \mathrm{ml}$ (approximately $85 \mathrm{mg}$ ) every $8 \mathrm{~h}$ for 3 days. Each dose was kept in the mouth for $1 \mathrm{~min}$ and then swallowed with glass of water $(150 \mathrm{ml})$, as in clinical practice. Voriconazole tablets and miconazole oral gel were self-administered by subjects except for the last doses, which were administered by the study personnel. Subject's intake of the premedication was verified using a mobile phone short message service. On study days, $1 \mathrm{~h}$ after the last dose of voriconazole or miconazole was ingested, all volunteers received $60 \mathrm{mg}$ oral dose of etoricoxib (Arcoxia $60 \mathrm{mg}$ tablet; Merck Sharp \& Dohme, Haarlem, Netherlands) at 9 a.m. with $150 \mathrm{ml}$ of water. During all phases, subjects fasted overnight before administration of etoricoxib and continued fasting until a standardized lunch was served $4 \mathrm{~h}$ after the intake of etoricoxib. Altogether, subjects stayed at the clinical laboratory from 7 a.m. until 9 p.m. on the study days. The subjects were forbidden to use any other medication for 14 days before and during the study and any drug known to cause enzyme induction or inhibition for 30 days prior the study. Caffeine, grapefruit juice, and alcohol-containing beverages were not allowed during the study.

Sampling and drug analysis

On the study days, a forearm vein of each subject was cannulated and kept patent with an obturator. Timed blood samples were drawn immediately before and at $0.5,1,1.5$, $2,2.5,3,4,5,6,8,12,24,48$, and $72 \mathrm{~h}$ after etoricoxib administration. After $12 \mathrm{~h}$, blood samples were drawn by venipuncture. Plasma was separated within $30 \mathrm{~min}$ and stored at $-70^{\circ} \mathrm{C}$ until analysis.

\section{Determination of drug concentrations}

Plasma concentrations of etoricoxib were determined after extraction into organic phase (shaking $1 \mathrm{ml}$ plasma with $6 \mathrm{ml}$ diethyl ether for $30 \mathrm{~min}$, followed by centrifugation) and high-performance liquid chromatography (HPLC) using ultraviolet (UV) detection at $284 \mathrm{~nm}$. HPLC separation was achieved with a liquid chromatography system equipped with a Chromolith Guard Cartridge RP$18 \mathrm{e}(10 \mathrm{~mm} \times 4.6 \mathrm{~mm})$ precolumn (Merck, Darmstadt, Germany) and RP Chromolith RP18 $(100 \mathrm{~mm} \times 4.6 \mathrm{~mm})$ column. The mobile phase was $0.1 \%$ acetic acid:acetonitrile (60:40), flow rate $1.5 \mathrm{ml} / \mathrm{min}$. Rofecoxib was used as an internal standard [15]. The recovery of both etoricoxib and the internal standard was $>90 \%$. The limit of etoricoxib 
quantification was $6 \mathrm{ng} / \mathrm{ml}$, and the day-to-day coefficient of variation $(\mathrm{CV})$ was $7.7 \%$ at $29.3 \mathrm{ng} / \mathrm{ml}, 2.2 \%$ at $290 \mathrm{ng} / \mathrm{ml}$, and $2.8 \%$ at $1078 \mathrm{ng} / \mathrm{ml}(n=13)$. All plasma samples from 0.5 to $72 \mathrm{~h}$ were quantifiable, and no etoricoxib was detected in any of the samples taken immediately before etoricoxib administration. Voriconazole or miconazole did not interfere with the determination of plasma etoricoxib.

Plasma voriconazole was quantified by HPLC as described earlier [16, 17]. The limit of quantification was $50 \mathrm{ng} / \mathrm{ml}$, and the day-to-day $\mathrm{CV}$ was $3.9 \%$ at $50 \mathrm{ng} / \mathrm{ml}$, $1.4 \%$ at $1,000 \mathrm{ng} / \mathrm{ml}$, and $0.4 \%$ at $10,000 \mathrm{ng} / \mathrm{ml}(\mathrm{n}=3)$. Plasma concentrations of miconazole were determined with an API 2000 liquid chromatography tandem mass spectrometry system (MDS Sciex, Toronto, Ontario, Canada) operating in positive turbo ion spray mode $[18,19]$. The ion transition monitored for miconazole was mass-to-charge ratio $(\mathrm{m} / \mathrm{z}) 417-161$. The limit of quantification for miconazole was $1.0 \mathrm{ng} / \mathrm{ml}$, and the day-to-day $\mathrm{CV}$ was $15.4 \%$ at $4.3 \mathrm{ng} / \mathrm{ml}(n=6), 7.9 \%$ at $37.0 \mathrm{ng} / \mathrm{ml}(n=6)$, and $7.4 \%$ at $143 \mathrm{ng} / \mathrm{ml}(n=5)$.

\section{Pharmacokinetic calculations}

Maximum drug concentration in plasma $\left(\mathrm{C}_{\max }\right)$ and time to maximum concentration $\left(\mathrm{t}_{\max }\right)$ for each subject were obtained directly from plasma-concentration data. The terminal log-linear phase of the plasma concentration time curve was identified visually for each subject. The elimination rate constant $\left(\mathrm{k}_{\mathrm{el}}\right)$ of etoricoxib was determined by a linear regression analysis of the log-linear part of the plasma concentration time. The area under the plasma concentration time curve (AUC) was calculated from zero to infinity $\left(\mathrm{AUC}_{0-\infty}\right)$ using the linear trapezoidal rule for the rising phase of the plasma concentration time curves and the logarithmic trapezoidal rule for the descending phase. The extrapolation of $\mathrm{AUC}_{0-\infty}$ was calculated by dividing the concentration in the last time point by $\mathrm{k}_{\mathrm{el}}$. The elimination half-life $\left(t_{1 / 2}\right)$ was calculated by the equation:

$\mathrm{t}_{1 / 2}=\ln 2 / \mathrm{k}_{\mathrm{el}}$

Pharmacokinetic data was analyzed using the WinNonlin pharmacokinetic program (version 4.1; Pharsight, Mountain View, CA, USA).

\section{Pharmacodynamic assessments}

Generation of $\mathrm{TxB}_{2}$ by platelets in spontaneously clotting whole blood, as an indicator of COX-1 activity, was measured as described previously [14]. On study days, blood samples for $\mathrm{TxB}_{2}$ assay were drawn before and at 1.5, 4, 8, 24 , and $48 \mathrm{~h}$ after etoricoxib administration. Blood samples were collected into glass tubes containing no anticoagulant and were immediately incubated for $1 \mathrm{~h}$ at $37^{\circ} \mathrm{C}$ to allow the blood to clot. Next, serum was collected and centrifuged and stored at $-70^{\circ} \mathrm{C}$ until assayed for $\mathrm{TxB}_{2}$. Serum $\mathrm{TxB}_{2}$ concentrations were determined by enzyme immunoassay kit (Amersham Thromboxane $\mathrm{B}_{2}$ Enzymeimmunoassay Biotrak $^{\mathrm{TM}}$ System, GE Healthcare, UK). The limit of quantification was $10 \mathrm{ng} / \mathrm{ml}$, and interassay CV was $17 \%$.

\section{Statistical analysis}

The pharmacokinetic variables of etoricoxib were compared using analysis of variance (ANOVA) for repeated measures, and a posteriori testing was performed by use of the Tukey test. $\mathrm{AUC}_{0-\infty}, \mathrm{C}_{\max }$, and $\mathrm{t}_{1 / 2}$ data were logarithmically transformed before analysis. As for bioequivalence testing, the geometric mean ratios (GMR) with $90 \%$ confidence intervals (CIs) were calculated. Bioequivalence was concluded if the $90 \%$ CIs of the geometric mean ratios for pharmacokinetic variables were within the acceptance limit of $0.8-1.25 . \mathrm{T}_{\max }$ was analyzed with Friedman's test, and Wilcoxon signed rank test was used for pairwise comparisons. The sample size was chosen to be sufficient to detect $30 \%$ change in the AUC of etoricoxib, assuming a withinsubject coefficient of variation of $30 \%$, with a power level of $80 \%$ and alpha level 5\% (Student's $t$ test). The change in $\mathrm{TxB}_{2}$ values from baseline was analyzed using fixed subject effects model, which included subject, treatment, period, time, period $\times$ time, and treatment $\times$ time effects. The baseline was the average $\mathrm{TxB}_{2}$ concentration, measured before the etoricoxib administration in every phase of the study. Time was used as a repeated effect assuming the unstructured covariance structure. The correlation of

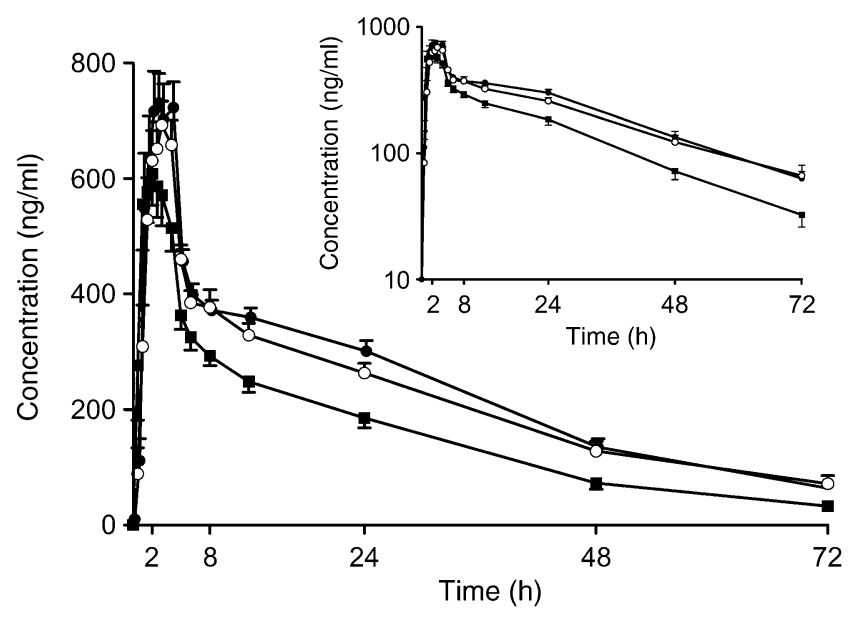

Fig. 1 Mean plasma concentrations ( \pm standard error of mean) of etoricoxib after a single $60-\mathrm{mg}$ oral dose in 12 healthy male subjects in control phase (filled squares $\mathbf{0})$ or after pretreatment with voriconazole (filled circles $\bullet$ ) or after pretreatment with miconazole oral gel (open circles $\circ$ ). The concentrations are shown both on arithmetic and semilogarithmic plots (inset) 
Table 1 The pharmacokinetic variables of etoricoxib in 12 healthy subjects after a single oral dose of 60 mg etoricoxib without pretreatment (control) or after pretreatment with miconazole oral gel or voriconazole

\begin{tabular}{|c|c|c|c|c|c|}
\hline \multirow[t]{2}{*}{ Variable } & \multicolumn{3}{|l|}{ Values for } & \multicolumn{2}{|c|}{ Geometric mean ratio $(90 \% \mathrm{CI})$ for } \\
\hline & Control & Miconazole & Voriconazole & Miconazole/control & Voriconazole/control \\
\hline $\operatorname{AUC}(\mu \mathrm{g} \mathrm{h} / \mathrm{ml})$ & $11.6(30 \%)$ & $19.6(36 \%)$ & $17.3(26 \%)$ & $1.69(1.46-1.92)$ & $1.49(1.37-1.61)$ \\
\hline $\mathrm{C}_{\max }(\mu \mathrm{g} / \mathrm{ml})$ & $0.68(25 \%)$ & $0.76(21 \%)$ & $0.81(28 \%)$ & $1.12(0.99-1.25)$ & $1.19(1.08-1.31)$ \\
\hline $\mathrm{t}_{1 / 2}(\mathrm{~h})$ & $18.1(30 \%)$ & $28.0(48 \%)$ & $20.6(34 \%)$ & $1.58(1.34-1.80)$ & $1.14(1.01-1.24)$ \\
\hline $\mathrm{t}_{\max }^{2}(\mathrm{~h})$ & $2(0.5-4.0)$ & $2.5(1.0-4.0)$ & $2(1.0-4.0)$ & & \\
\hline
\end{tabular}

The results are geometric means and coefficient of variation $(\mathrm{CV})$ (median with range for $\mathrm{t}_{\max }$ )

$A U C$ area under plasma concentration time curve extrapolated to infinity, $C_{\max }$ maximum plasma concentration, $t_{1 / 2}$ elimination half-life, $t_{\max }$ time to maximum plasma concentration, $C I$ confidence interval

voriconazole and miconazole AUC with the ratio of etoricoxib AUC in the voriconazole and in the miconazole phases to the etoricoxib AUC in the control phase was analyzed using Spearman rank test. Statistical analysis of pharmacokinetic parameters were carried out using statistical program SYSTAT for Windows (version 10.2; Systat Software, Richmond, CA, USA), and statistical analysis of pharmacodynamic parameters were carried out using SAS System for Windows, release 9.1 (SAS Institute Inc., Cary, NC, USA). The chosen statistical significance level was $P<0.05$.

\section{Results}

All 12 subjects completed the study according to the protocol. Their mean plasma concentrations of etoricoxib as a function of time during different phases of the study are illustrated in Fig. 1.

Pretreatment with miconazole oral gel resulted in a 1.69fold increase $(P<0.001)$ in the etoricoxib $\mathrm{AUC}_{0-\infty}$. The increase was seen in all 12 subjects, and the greatest increase was 3.1-fold (range 1.3- to 3.1-fold) (Table 1, Fig. 2). Furthermore, $t_{1 / 2}$ of etoricoxib was prolonged from 18 to $28 \mathrm{~h}(P<0.01)$. The $90 \%$ CIs for the geometric mean $\mathrm{AUC}_{0-\infty}$ and $\mathrm{t}_{1 / 2}$ ratios of etoricoxib (with/without mico- nazole) were $1.46-1.92$ and $1.34-1.80$, respectively, and were outside the bioequivalence acceptance limits (Table 1). There was no change in $\mathrm{C}_{\max }$ or $\mathrm{t}_{\max }$ of etoricoxib after miconazole oral gel pretreatment (Table 1, Fig. 2).

Voriconazole pretreatment increased the mean $\mathrm{AUC}_{0-\infty}$ and $\mathrm{C}_{\max }$ of etoricoxib 1.49-fold $(P<0.01)$ and 1.19-fold $(P<0.05)$, respectively, compared with the corresponding values in the control phase (Table 1). The increase of etoricoxib $\mathrm{AUC}_{(0-\infty)}$ was evident in all 12 subjects, the greatest increase being 2.0-fold (range 1.2- to 2.0-fold) (Fig. 2). The $90 \%$ CIs for the geometric mean $\mathrm{AUC}_{0-\infty}$ and $\mathrm{C}_{\max }$ ratios of etoricoxib (with/without voriconazole) were $1.37-1.61$ and $1.08-1.31$, respectively, and were outside the bioequivalence acceptance limits (Table 1). The prolongation of elimination $t_{1 / 2}$ of etoricoxib was seen in ten out of 12 subjects, and the mean prolongation was $14 \%$, which did not show to be statistically singificant. $\mathrm{T}_{\max }$ remained unaffected by voriconazole pretreatment (Table 1, Fig. 2).

The effect of miconazole on the pharmacokinetics of etoricoxib was comparable with that of voriconazole, the geometric mean $\mathrm{AUC}_{0-\infty}$ and $\mathrm{C}_{\max }$ ratios of etoricoxib (miconazole treatment/voriconazole treatment) being 1.13 $(90 \% \mathrm{CI} ; 1.00-1.30, P>0.05)$ and $0.94(90 \% \mathrm{CI} ; 0.85-$ $1.07, P>0.05)$, respectively. The $\mathrm{t}_{1 / 2}$ of etoricoxib was longer in the miconazole phase, the GMR of etoricoxib $t_{1 / 2}$
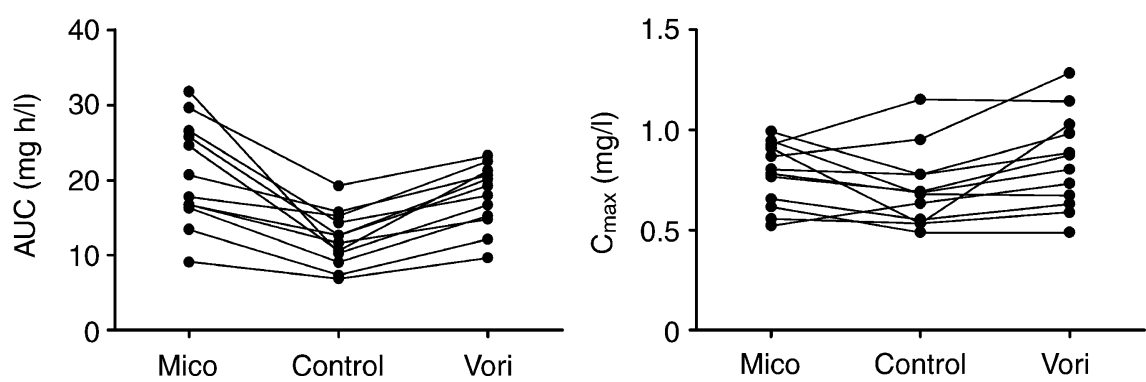

Fig. 2 Individual values for area under the plasma concentration-time curve (AUC), maximum concentration $\left(\mathrm{C}_{\max }\right)$, and elimination halflife $\left(t_{1 / 2}\right)$ after the administration of $60 \mathrm{mg}$ etoricoxib either alone

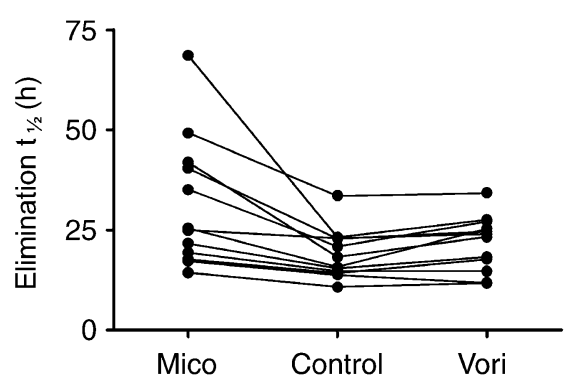

(Control) or after pretreatment with miconazole oral gel (Mico) or with voriconazole (Vori) 
Table 2 The pharmacokinetic variables of voriconazole and miconazole in 12 healthy subjects

\begin{tabular}{|c|c|c|c|c|}
\hline Pretreatment & AUC (ng h/ml) & $\mathrm{C}_{\max }(\mathrm{ng} / \mathrm{ml})$ & $\mathrm{t}_{1 / 2}(\mathrm{~h})$ & $\mathrm{t}_{\max }(\mathrm{h})$ \\
\hline Voriconazole & $36,700 \pm 32,400$ & $2,120 \pm 779$ & $10.6 \pm 4.07$ & $1(1-3)$ \\
\hline Miconazole & $778 \pm 503$ & $83.3 \pm 54.6$ & $22.3 \pm 10.3$ & $1(1-4)$ \\
\hline
\end{tabular}

Voriconazole was given for 2 days and miconazole oral gel for 3 days. Pharmacokinetic variables were determined after the last dose of voriconazole and miconazole, respectively. The results are mean \pm standard deviation (median with range for $t_{\max }$ )

$A U C$ area under plasma concentration time curve extrapolated to infinity, $C_{\max }$ maximum plasma concentration, $t_{1 / 2}$ elimination half-life, $t_{\max }$ time to maximum plasma concentration

(miconazole treatment/voriconazole treatment) being 1.36 (90\% CI; 1.19-1.63, $P<0.01)$.

The pharmacokinetic data of voriconazole and miconazole are shown in Table 2. Plasma concentrations of voriconazole and miconazole, measured before and after their last doses, indicated a good compliance in their ingestion. The mean $\mathrm{C}_{\max }, \mathrm{AUC}_{(0-\infty)}$, and $\mathrm{t}_{1 / 2}$ of voriconazole were $2,118 \mathrm{ng} / \mathrm{ml}, 36,700 \mathrm{ng} \mathrm{h} / \mathrm{ml}$, and $10.6 \mathrm{~h}$, respectively. The corresponding values for miconazole were $83.3 \mathrm{ng} / \mathrm{ml}, 778 \mathrm{ng} \mathrm{h} / \mathrm{ml}$, and $22.3 \mathrm{~h}$, respectively. There was no significant linear correlation between the AUC of voriconazole or miconazole and the ratio of the AUC of etoricoxib during the voriconazole or miconazole phase to that during the control phase (data not shown).

Figure 3 shows mean percent inhibition from baseline of $\mathrm{TxB}_{2}$ at different time points after ingestion of etoricoxib during three phases of the study. Baseline serum $\mathrm{TxB}_{2}$ levels were similar in each study phase; $201 \pm 106 \mathrm{ng} / \mathrm{ml}$, $190 \pm 68 \mathrm{ng} / \mathrm{ml}$, and $176 \pm 85 \mathrm{ng} / \mathrm{ml}$ (mean \pm standard deviation) ( $P>0.05$ for difference) prior to ingestion of etoricoxib during the control phase, voriconazole phase, and miconazole phase, respectively. Compared with the individual $\mathrm{TxB}_{2}$ baseline values, no statistically significant inhibition of $\mathrm{TxB}_{2}$ generation was observed at any time point after ingestion of etoricoxib alone or after etoricoxib with voriconazole or miconazole.

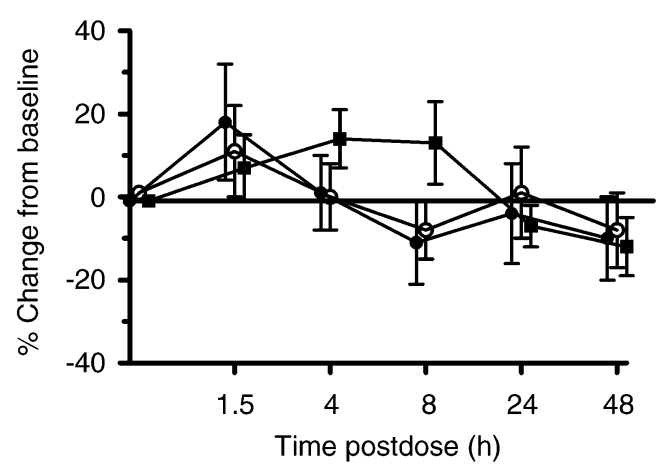

Fig. 3 Mean percent inhibition ( \pm standard error of mean) of thromboxane $\mathrm{B}_{2}\left(\mathrm{TxB}_{2}\right)$ generation from baseline at selected time points by $60 \mathrm{mg}$ etoricoxib either given alone (filled squares $\mathbf{m}$ ) or after pretreatment with voriconazole (filled circles $\bullet$ ) or miconazole oral gel (open circles $\circ$ )
During voriconazole pretreatment, four of the 12 subjects reported visual disturbances. Transient altered perception of light and photophobia were experienced shortly after ingesting voriconazole. In addition, one subject suffered from insomnia after the evening dose of voriconazole. No other clinically relevant adverse effects were recorded during the study.

\section{Discussion}

Both miconazole and voriconazole moderately affected the pharmacokinetics of etoricoxib. Miconazole oral gel increased the exposure to single dose of etoricoxib 1.7-fold as judged by $\mathrm{AUC}_{0-\infty}$ and prolonged the $\mathrm{t}_{1 / 2}$ of etoricoxib 1.6-fold but had only minimal effect on the $\mathrm{C}_{\max }$ of etoricoxib, which strongly suggests that the interaction between miconazole and etoricoxib occurs mainly during the elimination of etoricoxib. Changes in the pharmacokinetics of etoricoxib were quite similar after systemic oral voriconazole, which increased the exposure to a single dose of etoricoxib 1.5-fold and slightly increased the $\mathrm{C}_{\max }$ and $t_{1 / 2}$ of etoricoxib. Despite increased etoricoxib concentrations in the miconazole and voriconazole phase, etoricoxib had no statistically significant inhibitory effect on the production of $\mathrm{TxB}_{2}$, an indicator of $\mathrm{COX}-1$ activity.

It has been estimated that about $75 \%$ of the dose of etoricoxib is cleared via CYP-mediated 6'-methyl hydroxylation. This reaction is mainly catalyzed by CYP3A (60\%), but the rest is catalyzed equally between CYP2C9, CYP2C19, CYP2D6, and CYP1A2 [2, 3]. Correspondingly, previous in vitro studies have indicated that miconazole is a nonselective inhibitor of several CYPs, namely CYP3A, 2C9, 2C19, 1A2, 2A6, and 2B6 [4-6]. In our study, after 3-day pretreatment with miconazole oral gel (3.5 $\mathrm{ml} \approx 85 \mathrm{mg}$ three times daily), miconazole plasma concentrations were quantifiable $(4 \mathrm{ng} / \mathrm{ml}$ or more, data not shown) up to $24 \mathrm{~h}$ after the last dose and were sufficient to cause similar increase in the concentrations of etoricoxib than systemic oral voriconazole. To our knowledge, this is the first controlled clinical trial investigating the effect of miconazole oral gel on CYP inhibition. The dosing schedule of the miconazole oral gel was selected to be 
close to the therapeutic regimen $(2.5 \mathrm{ml}$ every $6 \mathrm{~h})$ and to allow the subjects not to take miconazole at night time. Our findings strongly support the idea that miconazole also, administered as an oral gel, has a potential to be absorbed and to cause drug interactions, presumably via CYP3A inhibition.

Earlier studies have shown that voriconazole causes a 9fold and 4-fold increase in the AUC of the CYP3A substrates midazolam (oral) and alfentanil (intravenous), respectively $[11,20]$. Both midazolam and alfentanil are almost solely metabolized by CYP3A, whereas the metabolism of etoricoxib is catalyzed not only by CYP3A but also by CYP2C9, 1A2, 2D6, and 2C19 [3]. This kind of involvement of multiple CYP enzymes, as well as the negligible first-pass metabolism of etoricoxib, possibly reduces the susceptibility of etoricoxib to the inhibitory effects of voriconazole.

In this study, administration of voriconazole and miconazole was not continued after etoricoxib ingestion. The mean $t_{1 / 2}$ of voriconazole was much shorter $(11 \mathrm{~h})$ compared with that of miconazole $(22 \mathrm{~h})$ or etoricoxib $(19 \mathrm{~h})$. Therefore, inhibition of CYP enzymes, particularly that caused by voriconazole, may have not lasted as long as in clinical situations, where voriconazole is used twice and miconazole oral gel four times a day. However, the magnitude of interaction between miconazole or voriconazole and etoricoxib is similar to that observed between ketoconazole, a well-known CYP3A inhibitor, and etoricoxib. Ketoconazole produced a 1.4-fold increase in the AUC of etoricoxib, which was administered on day 7 of an 11-day ketoconazole course in healthy subjects [21]. Thus, it is unlikely that notable underestimation in the magnitude of interactions observed in the this study exists.

In this study, 1.5- to 1.7 -fold mean increase in the exposure to a single dose of etoricoxib did not cause any obvious adverse effects in healthy young adults. In addition, we found that whether given alone or with voriconazole tablets or with miconazole oral gel, etoricoxib did not inhibit COX-1, as indicated by nonsignificant changes in the platelet $\mathrm{TxB}_{2}$ generation among the study phases. These findings are in accordance with the previous study, that even supratherapeutic doses of etoricoxib (500 mg single dose, $150 \mathrm{mg}$ daily for 9 days) are well tolerated and that etoricoxib maintains its COX-2 selectivity even after high doses [22]. Accordingly, it is unlikely that short-term concomitant use of etoricoxib with miconazole oral gel or voriconazole increases the risk for COX-1-related adverse effects, such as gastrointestinal disturbances, of NSAIDs. As with other coxibs, etoricoxib seems to carry some potential cardiovascular and renal risks, particularly when used at high doses for prolonged periods [23, 24]. However, whether long-term concomitant use of etoricoxib with voriconazole or miconazole predisposes patients for these adverse effects cannot be deduced from this study.

In conclusion, both oral voriconazole and miconazole oral gel caused a moderate increase in exposure to etoricoxib but did not induce loss of COX-2 selectivity of etoricoxib. Dose adjustment of etoricoxib is most likely not needed when single doses of etoricoxib are coadministered with voriconazole or miconazole, but lower doses of etoricoxib may be adequate for patients receiving voriconazole to gain pain relief. Finally, clinicians should be aware that miconazole oral gel, also, is a preparation that potentially may cause interactions with drugs metabolized by CYP3A.

Acknowledgments This work was supported by Turku University Hospital research fund EVO 13390 (Laine) EVO 13821 (Olkkola). Mr. Tero Vahlberg is thanked for his assistance in statistical issues. Mrs. Elina Kahra is thanked for her skilful assistance in organizing the study.

\section{References}

1. Agrawal NG, Porras AG, Matthews CZ, Rose MJ, Woolf EJ, Musser BJ, Dynder AL, Mazina KE, Lasseter KC, Hunt TL, Schwartz JI, McCrea JB, Gottesdiener KM (2003) Single- and multiple-dose pharmacokinetics of etoricoxib, a selective inhibitor of cyclooxygenase-2, in man. J Clin Pharmacol 43:268-276

2. Rodrigues AD, Halpin RA, Geer LA, Cui D, Woolf EJ, Matthews CZ, Gottesdiener KM, Larson PJ, Lasseter KC, Agrawal NG (2003) Absorption, metabolism, and excretion of etoricoxib, a potent and selective cyclooxygenase- 2 inhibitor, in healthy male volunteers. Drug Metab Dispos 31:224-232

3. Kassahun K, McIntosh IS, Shou M, Walsh DJ, Rodeheffer C, Slaughter DE, Geer LA, Halpin RA, Agrawal N, Rodrigues AD (2001) Role of human liver cytochrome P4503A in the metabolism of etoricoxib, a novel cyclooxygenase-2 selective inhibitor. Drug Metab Dispos 29:813-820

4. Niwa T, Shiraga T, Takagi A (2005) Effect of antifungal drugs on cytochrome P450 (CYP) 2C9, CYP2C19, and CYP3A4 activities in human liver microsomes. Biol Pharm Bull 28:1805-1808

5. Niwa T, Inoue-Yamamoto S, Shiraga T, Takagi A (2005) Effect of antifungal drugs on cytochrome P450 (CYP) 1A2, CYP2D6, and CYP2E1 activities in human liver microsomes. Biol Pharm Bull 28:1813-1816

6. Zhang W, Ramamoorthy Y, Kilicarslan T, Nolte H, Tyndale RF, Sellers EM (2002) Inhibition of cytochromes P450 by antifungal imidazole derivatives. Drug Metab Dispos 30:314-318

7. O'Reilly RA, Goulart DA, Kunze KL, Neal J, Gibaldi M, Eddy AC, Trager WF (1992) Mechanisms of the stereoselective interaction between miconazole and racemic warfarin in human subjects. Clin Pharmacol Ther 51:656-667

8. Ariyaratnam S, Thakker NS, Sloan P, Thornhill MH (1997) Potentiation of warfarin anticoagulant activity by miconazole oral gel. BMJ 314:349

9. Pemberton MN, Oliver RJ, Theaker ED (2004) Miconazole oral gel and drug interactions. Br Dent J 196:529-531

10. Silingardi M, Ghirarduzzi A, Tincani E, Iorio A, Iori I (2000) Miconazole oral gel potentiates warfarin anticoagulant activity. Thromb Haemost 83:794-795

11. Saari TI, Laine K, Leino K, Valtonen M, Neuvonen PJ, Olkkola KT (2006) Effect of voriconazole on the pharmacokinetics and 
pharmacodynamics of intravenous and oral midazolam. Clin Pharmacol Ther 79:362-370

12. Purkins L, Wood N, Kleinermans D, Nichols D (2003) Voriconazole potentiates warfarin-induced prothrombin time prolongation. Br J Clin Pharmacol 56(Suppl 1):24-29

13. Theuretzbacher U, Ihle F, Derendorf H (2006) Pharmacokinetic/ pharmacodynamic profile of voriconazole. Clin Pharmacokinet 45:649-663

14. Brideau C, Kargman S, Liu S, Dallob AL, Ehrich EW, Rodger IW, Chan CC (1996) A human whole blood assay for clinical evaluation of biochemical efficacy of cyclooxygenase inhibitors. Inflamm Res 45:68-74

15. Chavez-Eng CM, Constanzer ML, Matuszewski BK (2000) Determination of rofecoxib (MK-0966), a cyclooxygenase-2 inhibitor, in human plasma by high-performance liquid chromatography with tandem mass spectrometric detection. J Chromatogr B Biomed Sci Appl 748:31-39

16. Gage R, Stopher DA (1998) A rapid HPLC assay for voriconazole in human plasma. J Pharm Biomed Anal 17:1449-1453

17. Pennick GJ, Clark M, Sutton DA, Rinaldi MG (2003) Development and validation of a high-performance liquid chromatography assay for voriconazole. Antimicrob Agents Chemother 47:23482350

18. Compas D, Touw DJ, de Goede PN (1996) Rapid method for the analysis of itraconazole and hydroxyitraconazole in serum by high-performance liquid chromatography. J Chromatogr B Biomed Appl 687:453-456
19. Roberts PH, Bersuder P (2006) Analysis of OSPAR priority pharmaceuticals using high-performance liquid chromatographyelectrospray ionisation tandem mass spectrometry. J Chromatogr 1134:143-150

20. Saari TI, Laine K, Leino K, Valtonen M, Neuvonen PJ, Olkkola KT (2006) Voriconazole, but not terbinafine, markedly reduces alfentanil clearance and prolongs its half-life. Clin Pharmacol Ther 80:502-508

21. Agrawal NG, Matthews CZ, Mazenko RS, Woolf EJ, Porras AG, Chen X, Miller JL, Michiels N, Wehling M, Schultz A, Gottlieb AB, Kraft WK, Greenberg HE, Waldman SA, Curtis SP, Gottesdiener KM (2004) The effects of modifying in vivo cytochrome P450 3A (CYP3A) activity on etoricoxib pharmacokinetics and of etoricoxib administration on CYP3A activity. J Clin Pharmacol 44: $1125-1131$

22. Dallob A, Hawkey CJ, Greenberg H, Wight N, De Schepper P, Waldman S, Wong P, DeTora L, Gertz B, Agrawal N, Wagner J, Gottesdiener K (2003) Characterization of etoricoxib, a novel, selective COX-2 inhibitor. J Clin Pharmacol 43:573-585

23. Andersohn F, Suissa S, Garbe E (2006) Use of first- and secondgeneration cyclooxygenase-2-selective nonsteroidal antiinflammatory drugs and risk of acute myocardial infarction. Circulation 113:1950-1957

24. Curtis SP, Ng J, Yu Q, Shingo S, Bergman G, McCormick CL, Reicin AS (2004) Renal effects of etoricoxib and comparator nonsteroidal anti-inflammatory drugs in controlled clinical trials. Clin Ther. 26:70-83 